\title{
Dermestes haemorrhoidalis Küster (Coleoptera, Dermestidae): Primeiro Registro para o Nordeste do Brasil
}

\author{
Wellington Emanuel dos Santos ${ }^{\bowtie}$, Ana Claudia Firmino Alves \& Antonio José Creão-Duarte
}

Laboratório de Entomologia, Departamento de Sistemática e Ecologia, Universidade Federal da Paraíba, e-mail: well-bio@hotmail.com (Autor para correspondência $^{\varpi}$ ), aninha-bio@hotmail.com, creaoduarte@yahoo.com.br.

\section{EntomoBrasilis 6 (3): 255 (2013)}

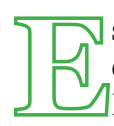

sse manuscrito é uma nota de correção da comunicação científica "Dermestes peruvianus Laporte (Coleoptera, Dermestidae): Primeiro Registro Para o Nordeste do Brasil" (SANTOS et al. 2012 - doi:10.12741/ebrasilis.v5i3.239 volume 5, número 3). Os espécimes tratados como Dermestes peruvianus Laporte no referido trabalho, segundo o especialista Dr. Jiří Háva (Czech University of Life Sciences, República Tcheca) tratam-se da espécie Dermestes haemorrhoidalis Küster. As duas espécies se diferenciam pelos seguintes caracteres (Háva \& KaLík 2005): D. haemorrhoidalis - élitro fosco, com pubescência bicolor (preto e amarelo) e cerdas longas que ultrapassam o ápice; $D$. peruvianus - élitro brilhante, com pubescência unicolor (marrom ao preto) e cerdas curtas que não ultrapassam o ápice.

D. haemorrhoidalis, assim como D. peruvianus, não foram antes coletadas no Nordeste do Brasil. Além disso, este é seu primeiro registro em carcaças na região Neotropical. Segundo Háva \& KALík (2005), a distribuição geográfica conhecida da espécie inclui: Europa, África do Sul, Burundi, Congo, Madagascar, Tanzânia, Zâmbia, Japão, Mongólia, Omã, Rússia, Argentina, Bolívia, Brasil, Peru e Uruguai. Adicionalmente, esse trabalho ressalva a importância de estudos em diversas regiões e ambientes, os quais trazem importantes novos registros (SANTOS et al. 2012; FARIAS et al. 2013), para o conhecimento da coleopterofauna associada a carcaças no Brasil.

\section{REFERÊNCIAS}

Farias, R.C.A.P., D. Dal-Bó, W.E. Santos, A.J. Creão-Duarte \& P.J. Thyssen, 2013. First Record of Scirtidae (Coleoptera) Associated with Decaying Carcasses in the Neotropical Region. EntomoBrasilis, 6: 171-172.

Háva, J. \& V. Kalík, 2005. Contribution to the Dermestes peruvianus species group from the Neotropical region (Coleoptera: Dermestidae). Baltic Journal of Coleopterology, 5: 87-98.

Santos, W.E., A.C.F. Alves \& A.J. Creão-Duarte, 2012. Dermestes peruvianus Laporte (Coleoptera, Dermestidae): primeiro registro para o Nordeste do Brasil. EntomoBrasilis, 5: 253254 .

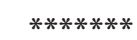

Como citar este artigo:

Santos, W.E., A.C.F. Alves \& A.J. Creão-Duarte, 2013. Dermestes haemorrhoidalis Küster (Coleoptera, Dermestidae): Primeiro Registro para o Nordeste do Brasil. EntomoBrasilis, 6(3): 255.

Acessível em: http://www.periodico.ebras.bio.br/ojs/index.php/ebras/article/view/389. doi:10.12741/ebrasilis.v6i3.389

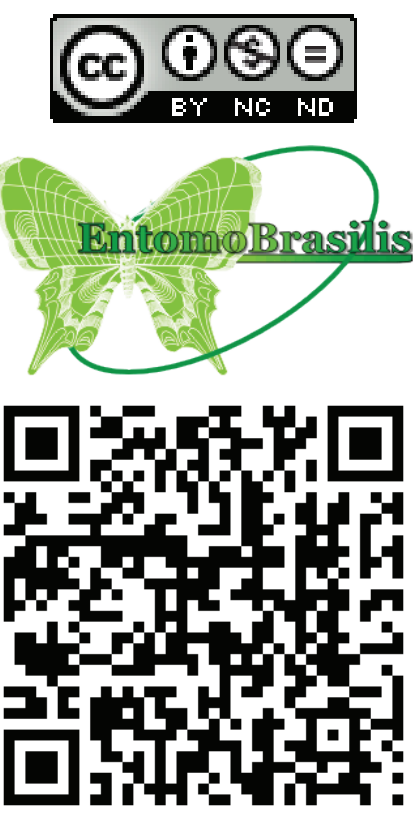

